\title{
Circadian Biorhythmicity in Normal Pressure Hydrocephalus - A Case Series Report
}

\author{
Leszek Herbowski \\ Department of Neurosurgery and Neurotraumatology, Independent Public Regional Hospital, Szczecin, Poland
}

Continuous monitoring of intracranial pressure is a well established medical procedure. Still, little is known about long-term behavior of intracranial pressure in normal pressure hydrocephalus. The present study is designed to evaluate periodicity of intracranial pressure over long-time scales using intraventricular pressure monitoring in patients with normal pressure hydrocephalus. In addition, the circadian and diurnal patterns of blood pressure and body temperature in those patients are studied. Four patients, selected with "probable" normal pressure hydrocephalus, were monitored for several dozen hours. Intracranial pressure, blood pressure, and body temperature were recorded hourly. Autocorrelation functions were calculated and cross-correlation analysis were carried out to study all the time-series data. Autocorrelation results show that intracranial pressure, blood pressure, and body temperature values follow bimodal (positive and negative) curves over a day. The cross-correlation functions demonstrate causal relationships between intracranial pressure, blood pressure, and body temperature. The results show that long-term fluctuations in intracranial pressure exhibit cyclical patterns with periods of about 24 hours. Continuous intracranial pressure recording in "probable" normal pressure hydrocephalus patients reveals circadian fluctuations not related to the day and night cycle. These fluctuations are causally related to changes in blood pressure and body temperature. The present study reveals the complete loss of the diurnal blood pressure and body temperature rhythmicities in patients with "probable" normal pressure hydrocephalus.

Key Words : Intracranial pressure · Normal pressure hydrocephalus · Circadian rhythm · Diurnal rhythm · Autocorrelation.

\section{INTRODUCTION}

Continuous monitoring of intracranial pressure (ICP) is a well established medical procedure that for 60 years has been considered a milestone in brain lesion management ${ }^{8)}$. Both cardio- and respiration-related rhythmic oscillations of ICP are thoroughly explored and evidence-based physiological phenomena. In contrast, little is known about long-time ICP fluctuations and biorhythmicity. Among those, the most ob- vious are the circadian rhythms associated with activity and sleep over circa 24-hour cycle. In healthy subjects, the normal diurnal/circadian biorhythms are controlled by the central circadian oscillator in hypothalamus (master clock), which adjusts itself to the light/dark cycle of the earth rotation. Thus far, three physiological parameters related to the time of day and night have been recognized as the most robust biomarkers of human circadian rhythm, namely the melatonin secretion, the cortisol level, and the body temperature (BT), the

- Received : April 11, $2021 \cdot$ Revised : May 28, $2021 \cdot$ Accepted : June 14, 2021

- Address for reprints : Leszek Herbowski

Department of Neurosurgery and Neurotraumatology, Independent Public Regional Hospital, 71-455 Szczecin, Arkonska 4, Poland

Tel : +48 91 8139770, Fax : +48 91 8139779, E-mail : leszek@herbowski.eu, ORCID : https://orcid.org/0000-0001-9113-3682

This is an Open Access article distributed under the terms of the Creative Commons Attribution Non-Commercial License (http://creativecommons.org/licenses/by-nc/4.0) which permits unrestricted non-commercial use, distribution, and reproduction in any medium, provided the original work is properly cited. 
measurement of BT providing the simplest and fastest practical method of monitoring ${ }^{5}$.

The present study is designed to evaluate the ICP periodicity over long-time scale with the help of intraventricular pressure monitoring in patients with normal pressure hydrocephalus. The circadian and diurnal behavior of BT and blood pressure (BP) is studied in the observed patients. Moreover, the causal relationship among all the recorded variables is analyzed and its nature is discussed.

\section{CASE REPORT}

\section{Study design}

All patients were treated at the Department of Neurosurgery and Neurotraumatology. Data analysis was performed retrospectively including medical charts obtained between 2010 and 2020. The study was approved by the Regional Ethical Board at Medical Council (Resolution No 04/KB/II) and written consent was taken from the patients.

\section{Patients}

The patients with "probable" normal pressure hydrocephalus included in the study met the criterium of having continuous ICP measurements performed for at least 36 hours preceding the infusion test procedure ${ }^{11)}$. Patients under the age of 18 years and with ICP over $20 \mathrm{mmHg}$ were excluded. When daily variations in atmospheric pressure (AP) exceeded 2 $\mathrm{mmHg}$ during measurements, the patient was excluded from the study. During the study period, all 37 patients underwent continuous ICP monitoring followed by an infusion test. Thirty patients were excluded due to the period of measurements shorter than 36 hours (the mean duration of the ICP recording in all above 30 patients was 25.1 hours; $95 \%$ confidence interval [CI], 18.1 to 32.1 hours). One patient was excluded due to the diagnosis of brain pseudotumor with ICP $>20 \mathrm{mmHg}$, one patient was excluded due to age of less than 18 years, and another patient was excluded because of unstable AP (AP changed from $767 \mathrm{mmHg}$ to $746 \mathrm{mmHg}$ during the ICP recording). The remaining four patients were enrolled for the analysis. None of the patients had symptoms of severe comorbidities.

\section{Monitoring and data recording}

The ICP measurements were performed with an intraventricular device (piezoelectric sensors by Codman Inc., Raynham, MA, USA and by Sophysa Inc., Crown Point, IN, USA) with the accuracy of $\pm 2 \%$ in the measured pressure. ICP was recorded continuously with an intracranial monitoring systems (ICP Express by Codman Inc. and ICP Pressio by Sophysa Inc.) in lying horizontal position (checked by inclinometer). The arterial BP was measured non-invasively in the brachial artery with an oscillometric device in maintained horizontal position in all patients and then the mean BP was calculated by adding one-third of the pulse pressure to the diastolic pressure. All the data from the ICP and BP measurements were evaluated by averaging over 1 hour periods. As a rule, during this study, AP was monitored since it is used as the zero reference point for each ICP record. The calibration was carried out intraoperatively. Consecutive hourly AP data were recorded directly with a weather station (Carrin KW9006W-SM by Carrin Electronics Company Ltd., Hong Kong), measurement's precision being $\pm 1 \mathrm{mmHg}$. BT was monitored in the frontal region above glabella by a non-contact thermometer (Thermofocus Essential 0700A2 by Tecnimed S.r.l., Varese, Italy) with measurement's precision of $\pm 0.2^{\circ} \mathrm{C}$. The temperature probe recorded distal skin temperature in degrees Celsius every hour during the study. All the recorded data was divided into the day (6:00 to 18:00) and night (18:00 to 6:00) cycles. On the basis of all the measurements, the hourly and day/night (cyclical) changes of the studied parameters were calculated.

\section{Analysis and statistics}

The measured data was analyzed using the Statistica ver. 10 software (StatSoft Inc., Tulsa, OK, USA). Student's t-test was performed when variables were normally distributed, otherwise the non-parametric (Mann-Whitney $U$ test) estimation was carried out. The relations between variables were analyzed with the Spearman correlation (r).

The concept of autocorrelation method and autocorrelation coefficients $(\mathrm{aR})$ were employed in the evaluation of the periodicity of the recorded measurements with the whitened and detrended analysis according to the applied algorithm ${ }^{12)}$. This algorithm is capable of indicating whether the periodicity of autocorrelation is related significantly and equal to the periodicity of ordered data of time series. It enables one to calculate both the frequency and the length of the cycle rhythm. An 
absolute requirement for analyzing the circadian time-series data is the observation period longer than 36 hours. The autocorrelation function was graphically represented by correlograms. The interval between the highest peaks (in the same phase) in a correlogram indicates the length of the cycle (period). In order to estimate the time-lagged relationships between the variables in question, the whitened and detrended cross-correlation analysis was performed, yielding the crosscorrelation coefficient (R).

The magnitudes of the observed data were estimated within 95\% CI. The differences between variables were considered statistically significant when a $p$-value was 0.05 or less.

\section{Results}

\section{General data}

The four subjects underwent the total of 216 hours of con-
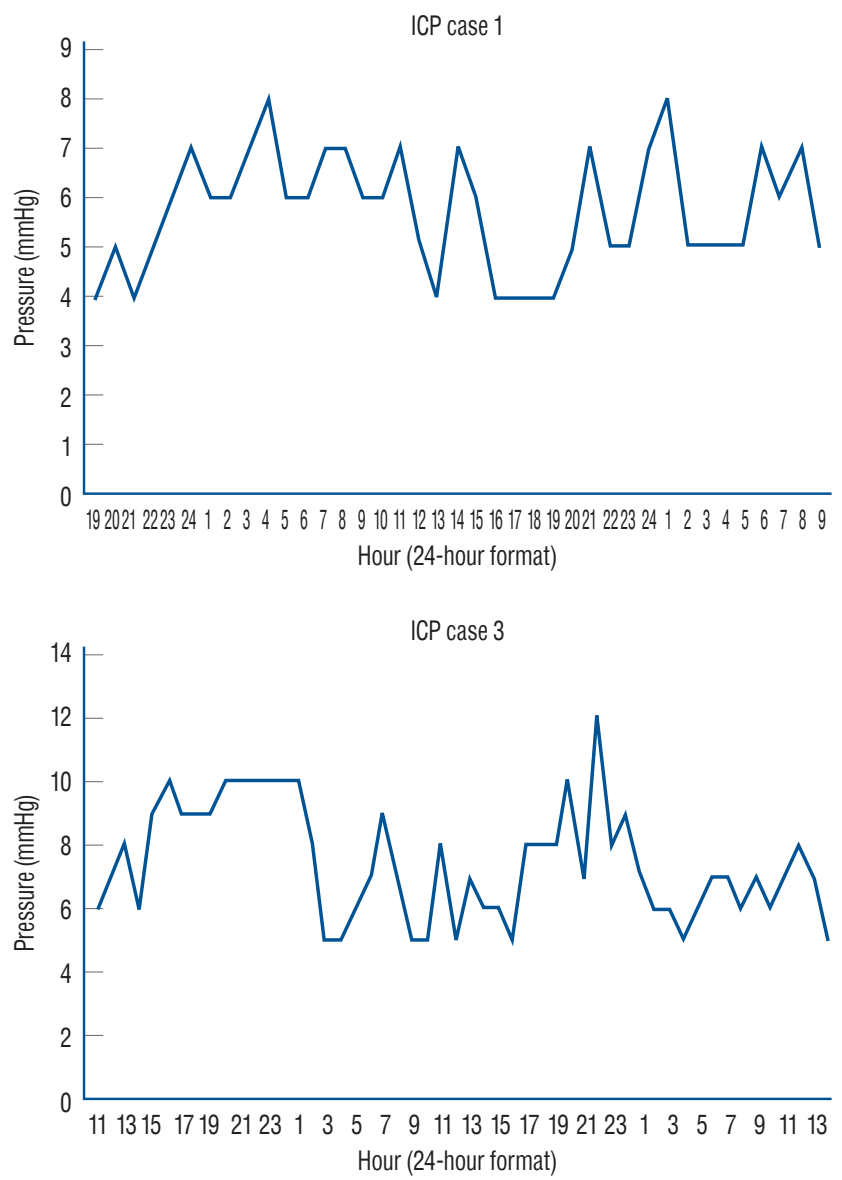

tinuous ICP recording (time range 39 to 66 hours). There were neither postoperative clinical complications nor technical problems. The mean ICP in all four patients was $9.5 \mathrm{mmHg}$ (95\% CI, 3.2 to $15.8 \mathrm{mmHg}$; minimum, $4 \mathrm{mmHg}$; maximum, $17 \mathrm{mmHg}$; range, $13 \mathrm{mmHg}$ ). The plotted data of hourly ICP in each case is displayed in Fig. 1. The study was performed under stable atmospheric pressure conditions (mean AP, 757.8 $\mathrm{mmHg}$; AP range of 754 to $761 \mathrm{mmHg}$ ). The mean BP in all above patients was $83.3 \mathrm{mmHg}$ (95\% CI, 72.1 to $94.4 \mathrm{mmHg}$; minimum, $53 \mathrm{mmHg}$; maximum, $104 \mathrm{mmHg}$; range, 51 $\mathrm{mmHg}$ ), the mean systolic BP was $103.9 \mathrm{mmHg}$ (minimum, $94 \mathrm{mmHg}$; maximum, $185 \mathrm{mmHg}$; range, $91 \mathrm{mmHg}$ ), the mean diastolic BP was $73 \mathrm{mmHg}$ (minimum, $47 \mathrm{mmHg}$; maximum, $86 \mathrm{mmHg}$; range, $39 \mathrm{mmHg}$ ). The mean BT was $36.4^{\circ} \mathrm{C}\left(95 \% \mathrm{CI}, 35.9^{\circ} \mathrm{C}\right.$ to $36.9^{\circ} \mathrm{C}$; minimum, $35.1^{\circ} \mathrm{C}$; maximum, $37.8^{\circ} \mathrm{C}$; range, $2.7^{\circ} \mathrm{C}$ ). The subjects' characteristics are compiled in Table 1.
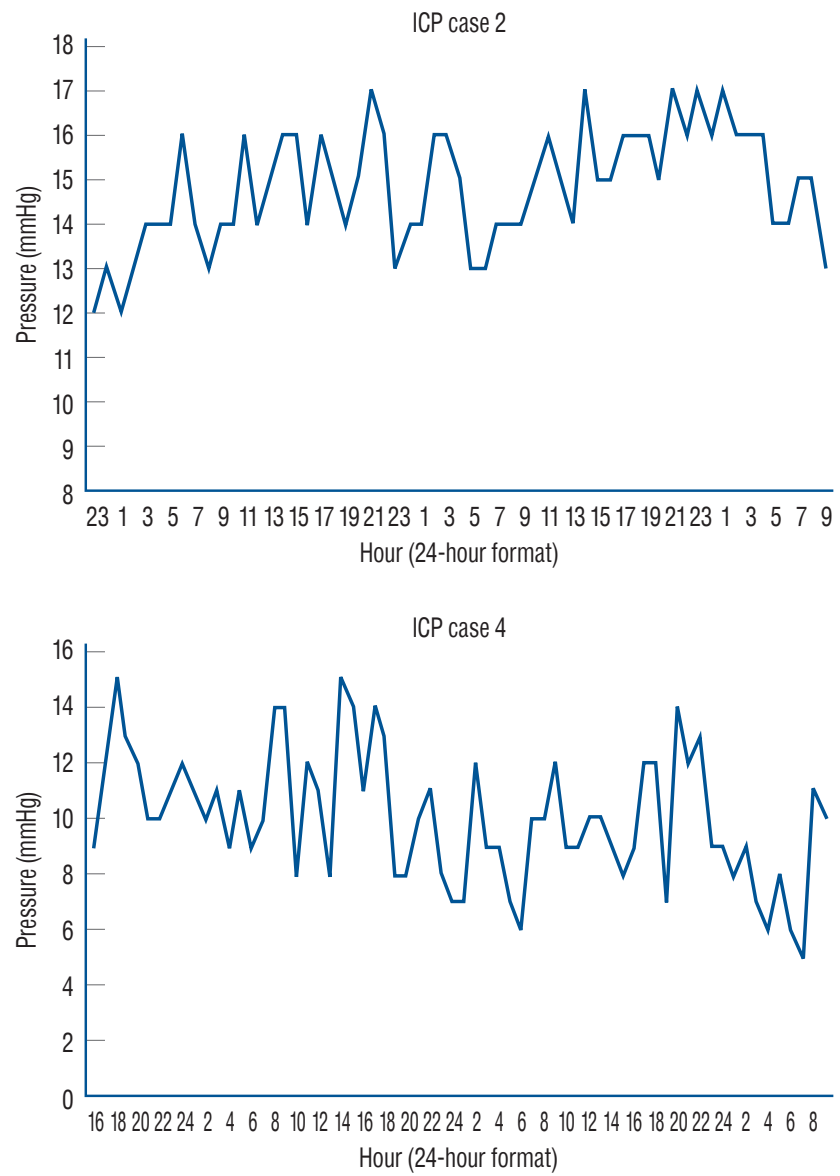

Fig. 1. The patterns of hourly ICP time series for the cases studied. On the vertical axis : the ICP values in mmHg. On the horizontal axis : the consecutive hours of study time. The ICP recordings begin at 19:00, 23:00, 11:00, and 16:00 for cases 1-4, respectively. ICP : intracranial pressure. 
In all the cases, the observations indicated a weak correlation between ICP and BP ( $\mathrm{r}=-0.16, p=0.035)$, a moderate cor- relation between ICP and BT ( $\mathrm{r}=0.31, p=0.018)$, and a weak correlation between BP and BT ( $\mathrm{r}=0.19, p=0.05)$.

Table 1. Clinical and demographic features

\begin{tabular}{lcccccccc}
\hline Case No. Gender & $\begin{array}{c}\text { Age } \\
\text { (years) }\end{array}$ & $\begin{array}{c}\text { Medical history } \\
\text { (years) }\end{array}$ & $\begin{array}{c}\text { Recording duration } \\
\text { (hours) }\end{array}$ & ICP $(\mathbf{m m H g})$ & BP $(\mathbf{m m H g})$ & BT $\left({ }^{\circ} \mathbf{C}\right)$ & $\begin{array}{c}\text { AP } \\
(\mathbf{m m H g})\end{array}$ \\
\hline 1 & F & 28 & 8 & 39 & $5.7(5.3-6.1)$ & $75.3(72.2-78.3)$ & $36.1(35.9-36.2)$ & 761 \\
2 & M & 64 & 5 & 59 & $14.8(14.5-15.2)$ & $86.7(84.9-88.4)$ & $36.5(36.4-36.5)$ & 756 \\
\hline 3 & F & 71 & 2 & 52 & $7.4(6.9-7.9)$ & $91.1(89.4-92.8)$ & $36.3(36.3-36.4)$ & 754 \\
4 & M & 74 & 5 & 66 & $10.1(9.5-10.7)$ & $79.9(78.3-81.5)$ & $36.8(36.7-36.9)$ & 760 \\
\hline
\end{tabular}

Values are presented as mean (95\% confidence interval) or number. ICP : intracranial pressure, BP : blood pressure, BT : body temperature, AP : atmospheric pressure, $\mathrm{F}$ : female, $\mathrm{M}$ : male
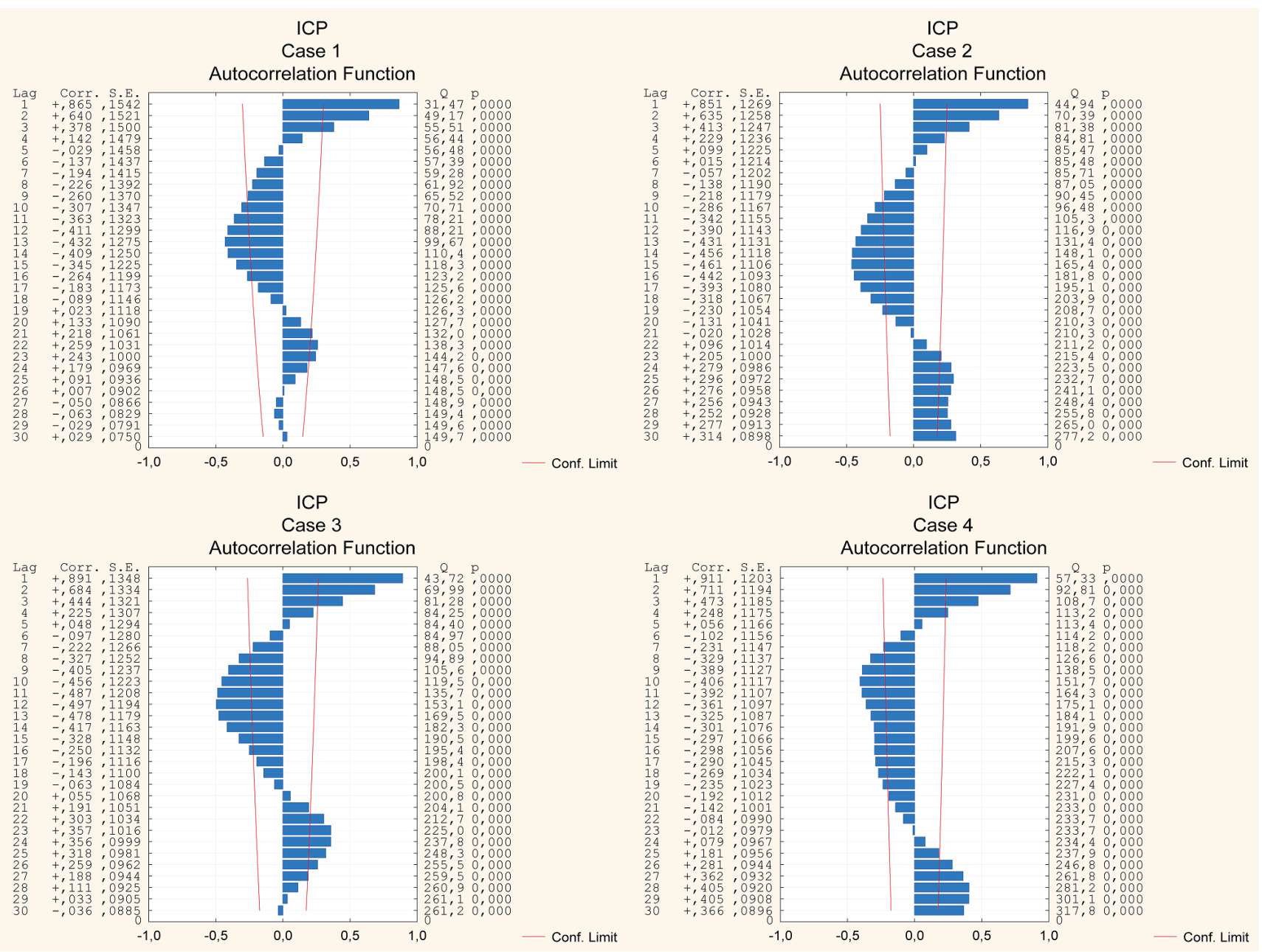

Fig. 2. Plots of autocorrelation functions of the original intracranial pressure (ICP) time series for all the cases studied. The data displayed include the delay (Lag), the autocorrelation coefficient for the delay (Corr.), the standard error (S.E.), the Q Box and Ljung coefficient (Q), and the level of significance of the result ( $p)$. On the horizontal axis : the confidence interval $(\alpha=0.05)$; the delay value indicates how many hours backwards the time series is compared with (e.g., 10 means comparison with 10 hours backwards); the confidence interval illustrates the spacing of two standard deviations from zero; the two red lines represent the $95 \%$ confidence interval (all the autocorrelations inside this "corridor" are virtually zero). 


\section{Day and night cycles}

The mean ICP in all four cases was $10.0 \mathrm{mmHg}$ during day (95\% CI, 9.3 to $10.7 \mathrm{mmHg}$ ) and $9.9 \mathrm{mmHg}$ during night (95\% CI, 9.3 to $10.6 \mathrm{mmHg}$ ). ICP did not vary significantly between day and night (Mann-Whitney $\mathrm{U}$ test, $p=0.08$ ). The mean BP was $86.2 \mathrm{mmHg}$ during day (95\% CI, 84.7 to 87.8 $\mathrm{mmHg}$ ) and $81.6 \mathrm{mmHg}$ during night (95\% CI, 80.0 to 83.2 $\mathrm{mmHg}$ ). BP did not vary significantly between day and night (Mann-Whitney $\mathrm{U}$ test, $p=0.61$ ). The mean $\mathrm{BT}$ was $36.5^{\circ} \mathrm{C}$ during day $\left(95 \% \mathrm{CI}, 36.4^{\circ} \mathrm{C}\right.$ to $\left.36.6^{\circ} \mathrm{C}\right)$ and $36.5^{\circ} \mathrm{C}$ during night $\left(95 \% \mathrm{CI}, 36.4^{\circ} \mathrm{C}\right.$ to $\left.36.5^{\circ} \mathrm{C}\right)$. BT did not vary significantly between day and night (Mann-Whitney $\mathrm{U}$ test, $p=0.10$ ).

\section{Autocorrelation}

The results of the autocorrelation analysis are presented graphically in Figs. 2-4 that depict both positive and negative values within the 30 -hour window, demonstrating either strong or moderate correlations in all the cases considered. A well-pronounced daily periodicity in BP can be seen in two cases, 1 and 3; whereas in cases 2 and 4 autocorrelations do not exhibit completed 24-hour cycles. Large-amplitude daily BT oscillations are found in three cases, 1-3. In case 4, the autocorrelation index does not reach the full 24-hour cycle period. The periods of the ICP cyclical wave patterns are as follows : 22 hours, 24 hours, 23 hours, and 28 hours in cases 1-4, respectively (see Fig. 5). Thus, the mean period of the ICP cyclical fluctuations is 24.25 hours (95\% CI, 20.1 to 28.4 hours). The observed ICP oscillations are significantly related to the biological rhythm with a period of about a day. Additionally, the autocorrelation results show the ICP, BP and BT values conforming to a bimodal (positive and negative) curves over a day.
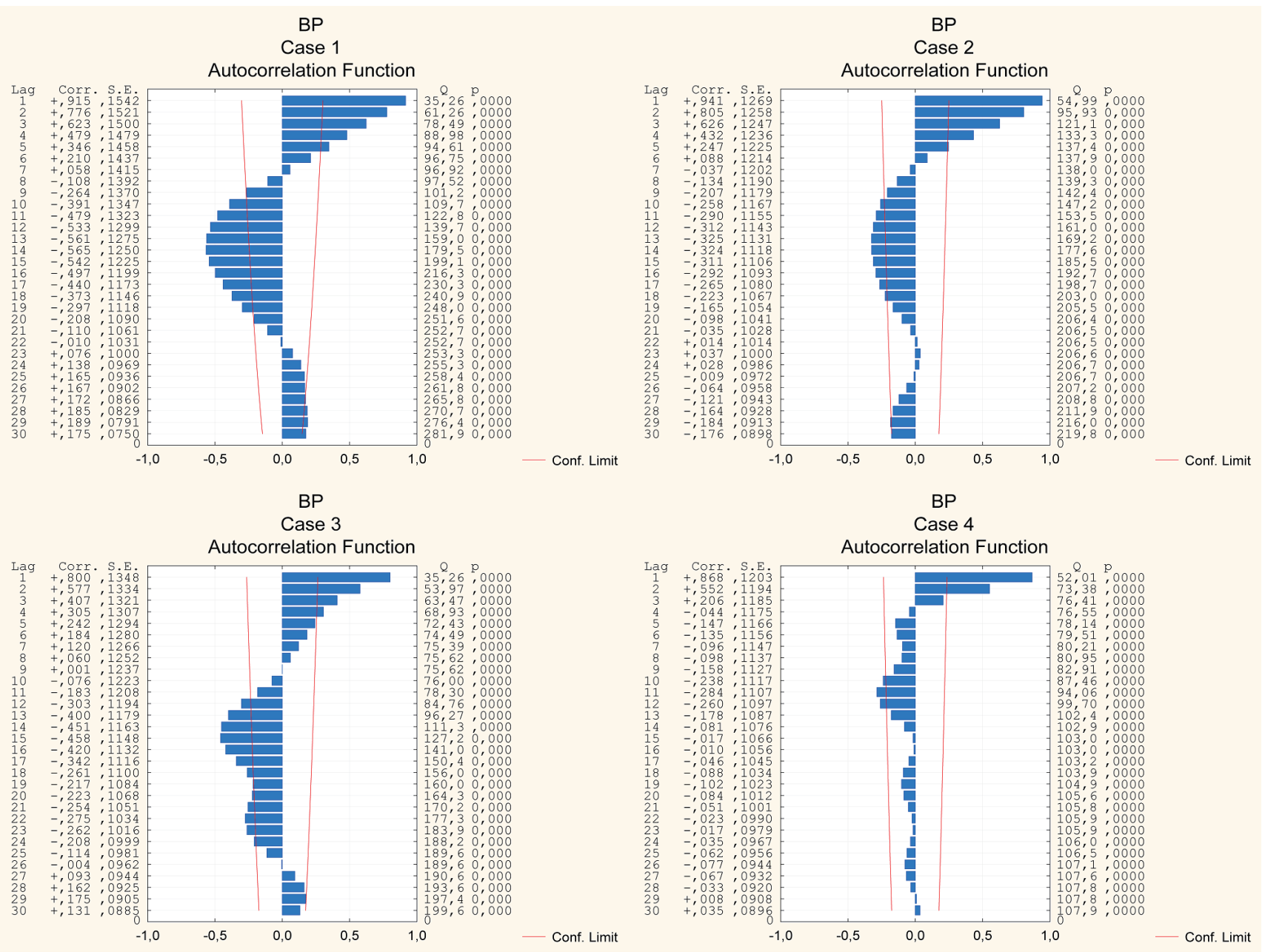

Fig. 3. Plots of autocorrelation functions of the original blood pressure (BP) time series for all the cases studied. 


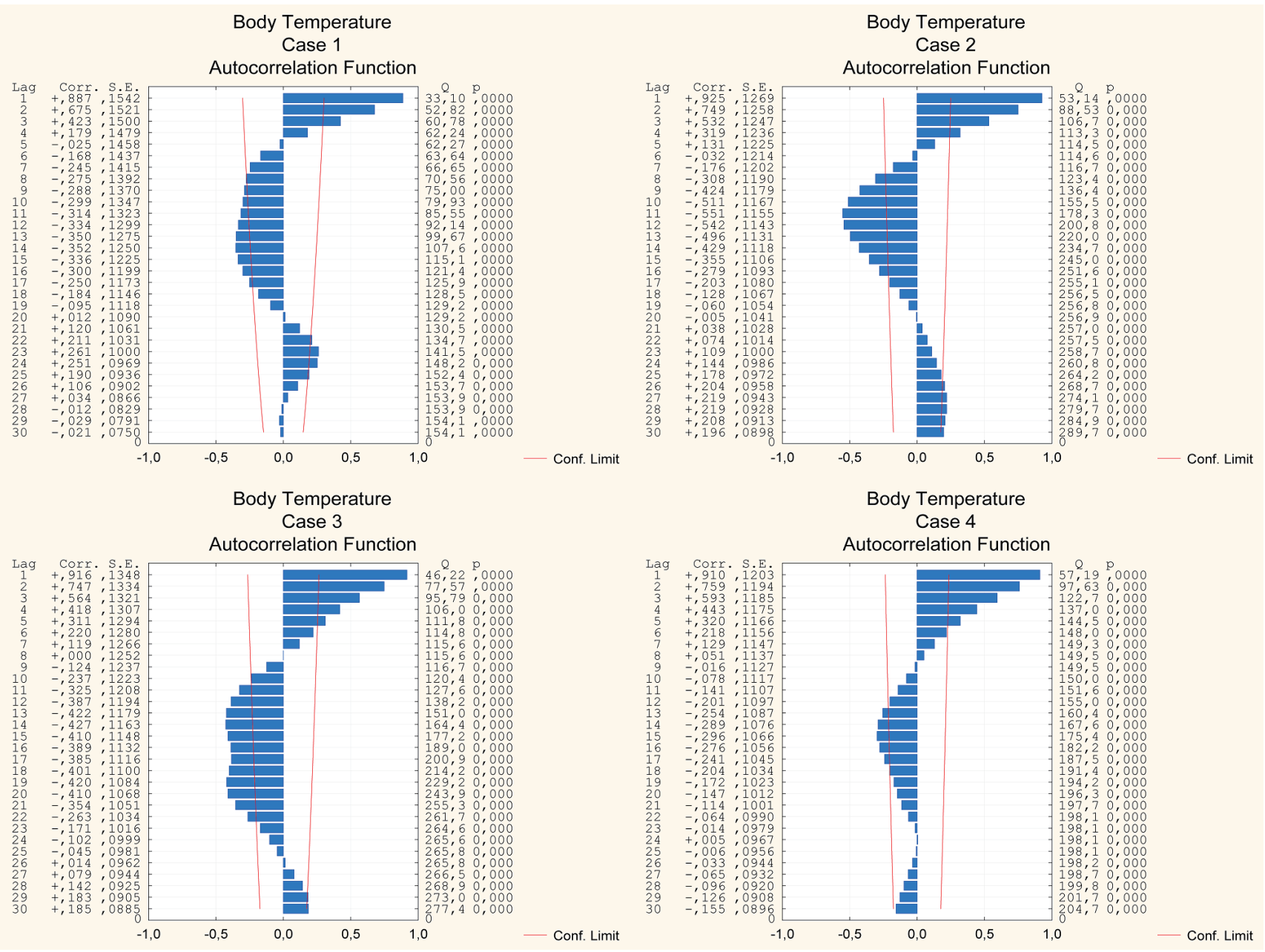

Fig. 4. Plots of autocorrelation functions of the original body temperature time series for all the cases studied.

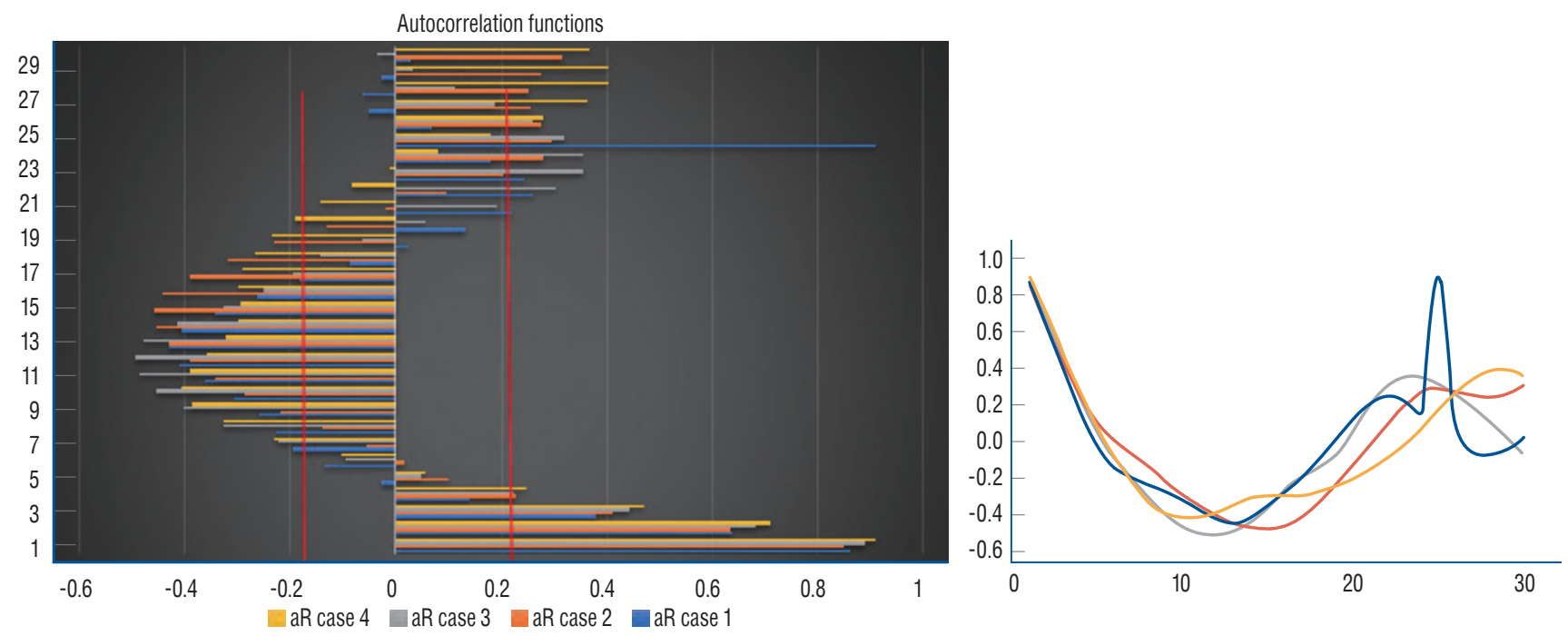

Fig. 5. Autocorrelation (aR) curves of intracranial pressur (ICP) for all the cases studied over the entire 30 hours pattern. The corresponding $95 \%$ confidence interval is marked as red solid lines. In the right panel, the calculated period of the ICP rhythm in the case 4 (in yellow) is slightly longer and closer to the upper circadian range (the horizontal axis : the time lag in hours, the vertical axis : the autocorrelation coefficient). 

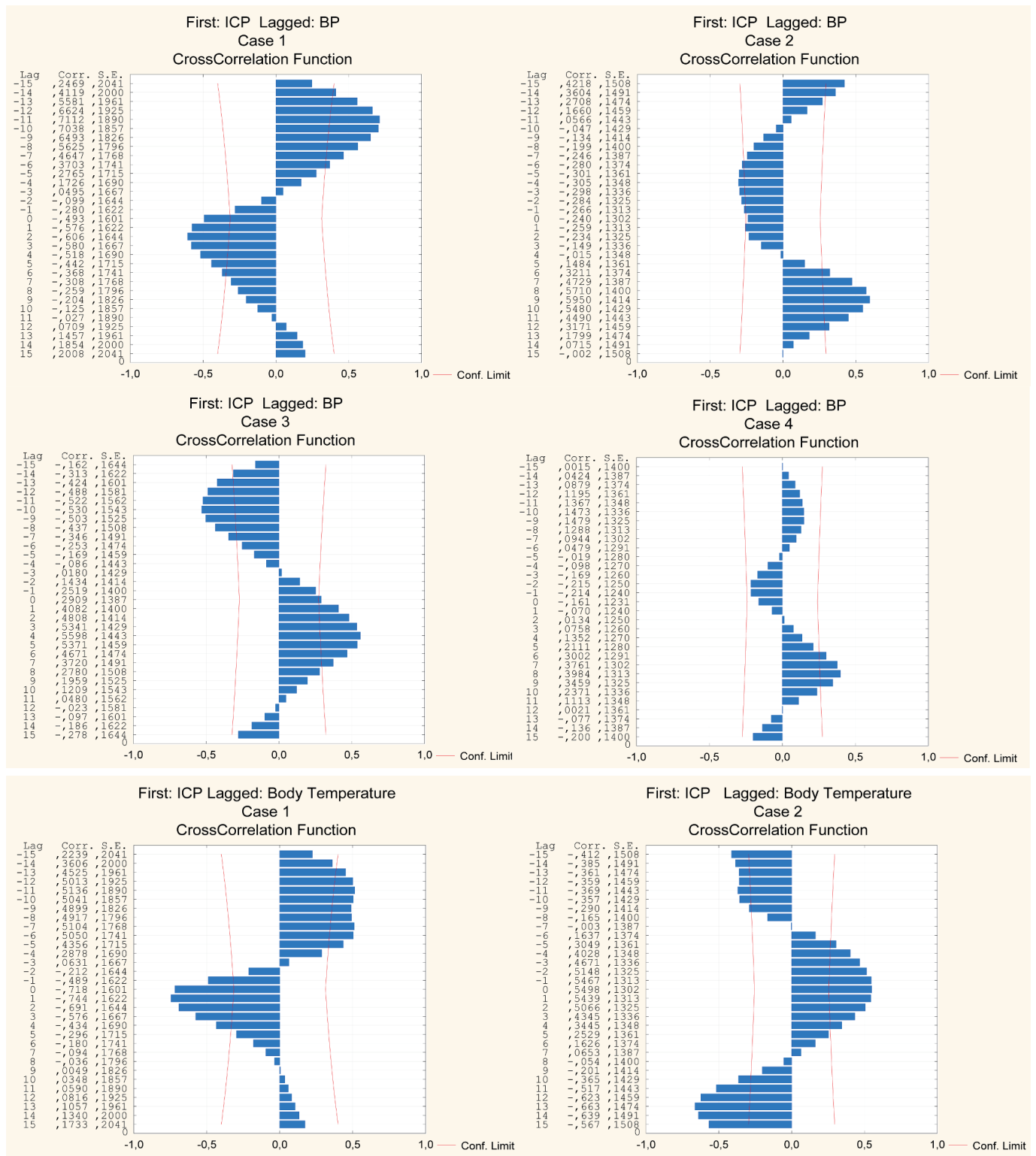

First: ICP Lagged: Body Temperature

First: ICP Lagged: Body Temperature Case 4
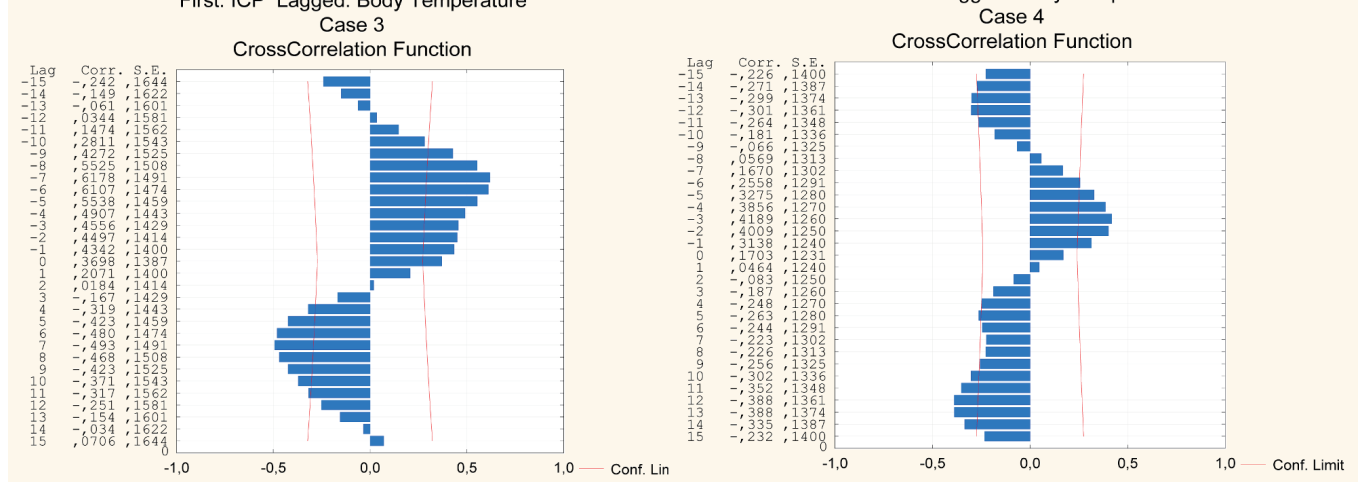

Fig. 6. The whitened and detrended cross-correlations of ICP/BP, ICP/BT and BP/BT (respectively from top to bottom) in patients 1-4, with the first patient on the left side of the figure and the fourth one on the right side. The corresponding $95 \%$ confidence interval is marked as red solid lines. There are statistically significant causal relations in all the cases between ICP and $B P(R=0.57, p<0.05)$, between ICP and $B T(R=0.61, p<0.05)$, and between $B P$ and $B T(R=0.657, p<0.05)$. ICP : intracranial pressure, $B P$ : blood pressure, $B T$ : body temperature. 

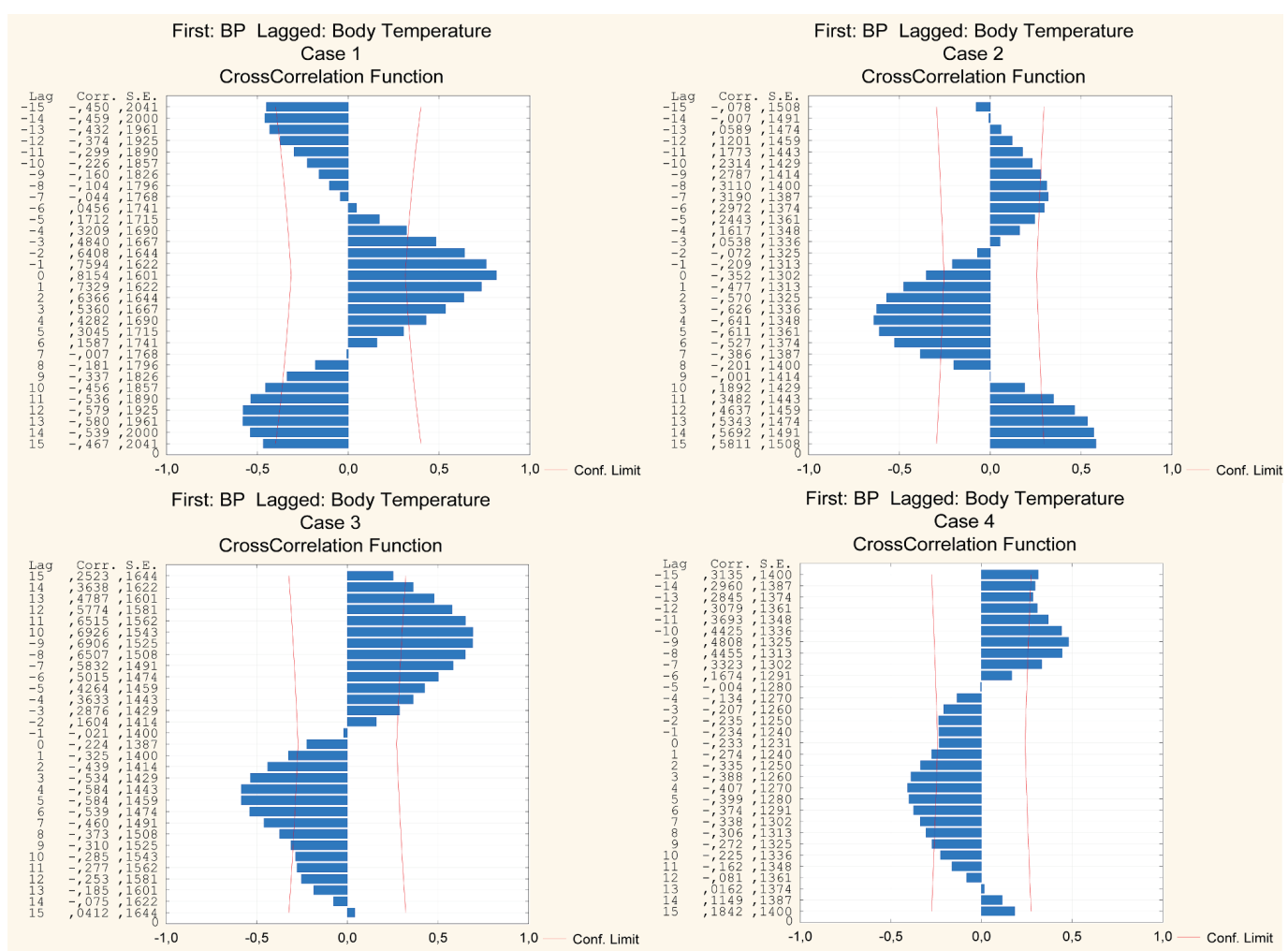

Fig. 6. Continued.

\section{Cross-correlation}

Fig. 6 displays the results of the cross-correlation analysis between all the variables in cases 1-4. The cross-correlation functions reflect significant causal relationships among ICP, BP, and BT. These data also exhibit cyclical patterns with periods amounting to approximately 1 day.

\section{DISCUSSION}

The term circadian rhythm refers to biological rhythmical periods completed within 24 hours (in the range of 20 to 28 hours or, exceptionally, even 13 to 34 hours) ${ }^{3,4)}$. The precise and reliable assessment of those periods was carried out by Czeisler et al. ${ }^{1)}$ in 24 healthy young and older human subjects under controlled conditions. The mean calculated circadian period was 24.18 hours with narrowed distribution of \pm 0.04 hour, which reflects the normal activity of hypothalamic suprachiasmatic nucleus ${ }^{1)}$.

The principal finding of this study is that of the average full cycle of the ICP fluctuation amounting to 24 hours and 15 minutes. Such cyclical oscillations are definitely considered circadian rhythms. The results also show that the long-term ICP fluctuations in analyzed patients with normal pressure hydrocephalus are not related to the day/night cycle. The importance of this observation stems from the absence in the medical literature of previous descriptions of circadian ICP patterns in normal pressure hydrocephalus in humans. There are only few reports on the ICP circadian rhythm in humans with brain injury. The earliest known study which noticed the presence of the circadian rhythm of ICP in humans is that of Kropyvnytskyy et al. ${ }^{9}$. Namely, in six out of 13 patients with severe traumatic brain injury (TBI), the ICP circadian rhythm was detected by the iterative cosinor method. The ICP circadian rhythm in TBI patients was definitely confirmed by Li et al. ${ }^{10)}$. Using the single cosinor method, these authors detected a circadian pattern of ICP in all the 62 studied patients with moderate or severe brain injury.

In contrast to single reports about ICP circadian periodicity, the circadian and diurnal fluctuations in BP and BT are well described physiological phenomena of human biorhythmicity. The loss of the BP and BT circadian period and diurnal pat- 
tern observed in long-term monitoring of the patients is a striking finding in the present study. Namely, significant BP variation during day/night cycle was detected in none of the patients, the observed fluctuations of BP not matching the circadian period in two patients. Similarly, BT did not exhibit significant diurnal changes related to the day/night cycle in all patients, whereas the wave period was out of the circadian range in one patient. Full circadian desynchronization of both BP and BT (the loss of diurnal rhythm and longer period than 30 hours) was noted in the case 4 , the full desynchronization of BP only in the case 2, and incomplete desynchronization (i.e., the diurnal loss of BP and BT rhythmicity) in other two cases.

The phenomenon of the loss of physiological patterns in the diurnal rhythm demonstrated in the cases presented in this paper is in line with that observed in acute cerebrovascular diseases and dementia observed by Jain and colleagues ${ }^{6}$, who reported the loss of circadian BP fluctuations in patients with acute stroke. Recent studies focused on the master clock aging demonstrated the loss of hypothalamus neurons, the associated robust reduction in the amplitude of the output signals by $50 \%$ in aged suprachiasmatic nucleus resulting in altering synaptic transmission and leading to desynchronization of circadian biorhythmicity ${ }^{2)}$. Perhaps, the main reason for complete desynchronization in the studied 74-year old patient (case 4) is the age-related master clock malfunction in the elderly.

The loss of the diurnal rhythmicity of ICP, BP and BT observed in the present study can be regarded as an associated symptom of the normal pressure hydrocephalus development. Especially crucial is the lack of diurnal BT variation in all the four patients as BT is the key biomarker of diurnal biorhythmicity in humans. This diurnal temperature rhythmicity is under control of the suprachiasmatic nucleus located directly under the bottom of the third ventricle, which can be disturbed functionally and structurally in hydrocephalus due to ventricle enlargement in the vicinity of the nucleus.

Although no strong correlations among ICP/BP, ICP/BT and $\mathrm{BP} / \mathrm{BT}$ were observed, statistically significant causal relations among these variables do exist. The lag (phase difference) behavior between the monitored variables is not unidirectional as it can be either positive or negative. Interestingly, the ICP circadian waves measured in this study precede the $\mathrm{BP}$ oscillations in one patient (case 1), while in other patients the relation is the opposite. Thus, there is a dual transfer function behavior between the arterial BP and ICP circadian rhythm. It is widely accepted that, in normal physiological circumstances, the arterial BP entering the cranium is a leading wave which impacts the ICP fluctuations. Thus, the situation when fluctuations in the output signals (ICP) precede fluctuations in the input signal (BP), as observed in this study, calls for explanation. Such erratic behavior of the relation between both waves in long-time scale may be caused by the disruption of the master clock due to ventricle enlargement. However, the underlying pathomechanisms are presently not known.

In summary, it is essential to consider the following phenomena encountered in the presented study as symptoms associated with the onset or development of normal pressure hydrocephalus : the disruption of the BP and BT circadian rhythms (outside of the range of entrainment), the loss of the BP and BT diurnal rhythmicity, and the loss of the ICP diurnal fluctuations. Such desynchronization of circadian/diurnal biorhythms is the sign of circadian pathology reflecting disturbances in the function of the master clock located in the hypothalamus at the bottom of the third ventricle. The recent studies, including those employing the diffusion tensor imaging, do not indicate direct pathological change within the anterior hypothalamus. Thus, it is reasonable to hypothesize that functional compression and stretching of the axons connecting with suprachiasmatic nucleus is the fundamental reason of biorhythmicity desynchronization ${ }^{7)}$. The circadian desynchronization in patients with "probable" normal pressure hydrocephalus is thus becoming an essential indicator of prognostic value.

The presented work has a few limitations. Firstly, a relatively small sample size of four patients with "probable" normal pressure hydrocephalus was studied. In order to confirm the reproducibility of the presented results, more studies should be conducted. Secondly, the cyclical ICP fluctuation should be measured over more than one cycle. A wider window for the time-series analysis is required. Thirdly, there was no control group since ICP recordings in healthy individuals are unavailable due to ethical reasons. All in all, more long-term ICP recordings should be collected in future. 


\section{CONCLUSION}

Continuous ICP recording in normal pressure hydrocephalus patients shows cyclical fluctuations with a period of about 24 hours. Thus, these fluctuations are considered circadian ICP rhythm but are not related to the day and night cycles. The circadian ICP fluctuations are found to be causally related to BP and BT changes. The disruption of the circadian BP and BT biorhythmicity indicates master clock desynchronization. This study shows a complete loss of the diurnal BP and BT rhythmicity in four observed patients with "probable" normal pressure hydrocephalus.

\section{CONFLICTS OF INTEREST}

No potential conflict of interest relevant to this article was reported.

\section{INFORMED CONSENT}

Informed consent was obtained from all individual participants included in this study.

\section{AUTHOR CONTRIBUTIONS}

\author{
Conceptualization : $\mathrm{LH}$ \\ Formal analysis : LH \\ Methodology : LH \\ Visualization : LH \\ Writing - original draft : $\mathrm{LH}$ \\ Writing - review \& editing : LH
}

\section{ORCID}

Leszek Herbowski https://orcid.org/0000-0001-9113-3682

\section{- Acknowledgements}

The author thanks Patrycja Herbowska-Tytro for help with the English translation and final preparation of the paper in terms of lexis and grammar.

\section{References}

1. Czeisler CA, Duffy JF, Shanahan TL, Brown EN, Mitchell JF, Rimmer DW, et al. : Stability, precision, and near-24-hour period of the human circadian pacemaker. Science 284 : 2177-2181, 1999

2. Farajnia S, Deboer T, Rohling JH, Meijer JH, Michel S : Aging of the suprachiasmatic clock. Neuroscientist $20:$ 44-55, 2014

3. Halberg F, Carandente F, Cornelissen G, Katinas GS : Glossary of chronobiology (author's transl). Chronobiologia 4 Suppl 1 : 1-189, 1977

4. Hassnaoui M, Pupier R, Attia J, Blanc M, Beauchaud M, Buisson B : Some tools to analyze changes of rhythms in biological time series. Biological Rhythm Research 29 : 353-366, 1998.

5. Hofstra WA, de Weerd AW : How to assess circadian rhythm in humans: a review of literature. Epilepsy Behav $13:$ 438-444, 2008

6. Jain S, Namboodri KKN, Kumari S, Prabhakar S : Loss of circadian rhythm of blood pressure following acute stroke. BMC Neurol $4: 1$, 2004

7. Keong NC, Pena A, Price SJ, Czosnyka M, Czosnyka Z, DeVito EE, et al. : Diffusion tensor imaging profiles reveal specific neural tract distortion in normal pressure hydrocephalus. PLoS One 12 : e0181624, 2017

8. Kim DR, Yang SH, Sung JH, Lee SW, Son BC : Significance of intracranial pressure monitoring after early decompressive craniectomy in patients with severe traumatic brain injury. J Korean Neurosurg Soc 55 : 2631, 2014

9. Kropyvnytskyy IV, Saunders FW, Klemfuss H : Circadian rhythm of cerebral perfusion pressure and intracranial pressure in head injury. Brain Inj $13:$ 45-52, 1999

10. Li X, Guan J, Hou W, Cheng S, Jiang Z, Wang, et al. : The circadian intracranial pressure would be a prognostic factor in traumatic brain injury? Biol Rhythm Res 47 : 823-832, 2016

11. Relkin N, Marmarou A, Klinge P, Bergsneider M, Black PM : Diagnosing idiopathic normal-pressure hydrocephalus. Neurosurgery 57 (3 Suppl) : S4-S16; discussion ii-v, 2005

12. Shuai $C$, Renyi $S$ : Autocorrelation algorithm to evaluate minimum periodicity of digital sequence. 2011 Fourth International Conference on Intelligent Computation Technology and Automation; 2011 Mar 28-29; Shenzhen, China. Los Alamitos : IEEE; 2011 Apr. 961-963 pp 